\title{
SeNTIDO Y ALCANCE DE LAS INVESTIGACIONES INTERNAS EN LA EMPRESA
}

[Purpose and Scope of Internal Investigations in Companies]

\author{
Juan Pablo Montiel*
}

\begin{abstract}
Resumen
En un contexto de notable expansión del fenómeno del "criminal compliance" en el plano práctico y científico, las investigaciones internas aparecen llamativamente como uno de los temas menos trabajados. Sin embargo, el interés de la doctrina ha crecido notablemente en los últimos años como consecuencia de su potencial relevancia en la atenuación y exclusión de la responsabilidad penal. La presente contribución acerca una introducción general en la que se delimitan conceptualmente las investigaciones internas (para distinguirlas de otros mecanismos similares, v.
\end{abstract}

\begin{abstract}
Within a context of remarkable expansion of the criminal compliance phenomenon, internal investigations seem to be the matters less dealt with, from a practical and scientific point of view. However, the interest of the doctrine has remarkably increased within the last years as a result of its potential importance in the attenuating circumstances and exclusion of criminal liability. This work is an approximate general introduction with a conceptual delimitation of the internal investigations (to differentiate them from other similar mechanisms, e.g.
\end{abstract}

RECibido el 3 de abril y ACEPTADo el 20 de mayo de 2013

* Becario de la Fundación Alexander von Humboldt en la Universidad ErlangenNürnberg, Alemania. Correo postal: Lehrstuhl für Strafrecht, Strafprozessrecht und Rechtsphilosophie (LS Kudlich), Universität Erlangen-Nürnberg, Schillerstraße 1, 91054 Erlangen, Alemania. Correo electrónico: jpmontiel@crimint.com.ar - juanpablo.montiel@gmail.com 
gr. medidas de control empresarial) y se analizan sus cuestiones más problemáticas en el terreno del Derecho penal y procesal penal; entre ellas, si el empresario está obligado a implementar estos procesos de "auto-limpieza" y en su caso cuándo, como así también si el principio nemo tenetur se ipsum accusare está vigente en este terreno.

\section{Palabras Clave}

Investigaciones internas - Investigaciones internas pre-judiciales - Investigaciones internas para-judiciales - Deber de investigar - Nemo tenetur se ipsum accusare - Niveles sospecha - Ordenanza procesal-penal empresarial. company control measures) and its most troublesome matters are analyzed within criminal and criminal procedural Law. Among these, if the businessperson is forced to implement these "self-cleaning" procedures, the question is when and if principle nemo tenetur se ipsum accusare is applicable in this scenario.

\section{KEYWORDS}

Internal investigations - Pre-judicial internal investigations - Para-judicial internal investigations - Duty to investigate - Nemo tenetur se ipsum accusare Suspicion levels - Company proceduralcriminal ordinance.

\section{Privatización del CONTROL DE LA CRIMINALIDAD E INVESTIGACIONES INTERNAS}

Cuando en nuestros días se aborda el fenómeno del "criminal compliance" parece difícil hablar de una privatización del control de la criminalidad ${ }^{1}$, sin una correspondiente privatización del proceso penal ${ }^{2}$. Así, del mismo

\footnotetext{
${ }^{1}$ Sieber, U., Programas de "Compliance" en el Derecho penal de la empresa. Una nueva concepción para controlar la criminalidad de empresa (trad. Abanto - Vásquez), en Urquizo Olaechea, J. - Abanto Vásquez, M. - Salazar Sánchez, N. (coordinadores), Dogmática penal de derecho penal económico y politica criminal Homenaje a Klaus Tiedemann (Lima, Fondo Editorial, 2011), p. 206; KnAuer, K., Interne Ermittlungen. Teil I: Grundlagen", en $Z W H ., 2$ (2012), p. 41. Parte de la doctrina entiende que, como consecuencia de esta privatización, las actuaciones del empresario en las investigaciones internas podría imputársele al Estado. Al respecto, KNIERIM, T., Erfordernisse und Grenzen der "internal investigations", en RотsсH (editor), Wissenschaftliche und praktische Aspekte der nationalen und internationalen Compliance-Diskussion (Baden-Baden, 2001), p. 85. Contrario a esta opinión: JAHN, M., Ermittlungen in Sachen Siemens - SEC, en StV., 1 (2009), p. 45.

${ }^{2}$ Nestler, N., "Internal investigations": Definition und rechtstatsächliche Erkenntnisse zu internen Ermittlung in Unternehmen, en KNIERIM, T. - RÜBENSTAHL, M. TsambiKaKIs, M. (editores), "Internal investigations". Ermittlungen im Unternehmen (Heidelberg y otras, C. F. Müller, 2013), números 16 ss.
} 
modo que encontramos cada vez mayores exigencias para que las empresas se auto-regulen e implementen sistemas idóneos de control y prevención de irregularidades, también asumen un papel cada vez más importante las prácticas que se implementan para investigar y eventualmente sancionar ilicitudes ${ }^{3}$. En este sentido, puede constatarse la existencia de un segundo sistema de regulación - paralelo al estatal-, que constriñe a las empresas a prevenir, descubrir y sancionar infracciones a la ley ${ }^{4}$.

Precisamente, en este proceso de privatización el proceso penal encontraría su equivalente funcional en las investigaciones internas. Esta equivalencia se muestra aún más claramente cuando se presta atención a los fines preventivos y de obtención de la verdad que persiguen las "internal investigations", en clara sintonía con los fines del proceso penal'. Además, una vez tomada la decisión de investigar la posible comisión de un delito, los abogados de la empresa (o bien abogados externos) deben recabar toda la evidencia posible y ponerla a disposición de la junta directiva, quien adoptará finalmente una decisión vinculante en el seno de la empresa. Desde esta perspectiva resulta muy difícil evitar no comparar esas actividades empresariales con las de un fiscal y un juez.

Sin embargo, y pese a las puntuales coincidencias que puedan existir, no debe perderse de vista que las investigaciones empresariales tienen una naturaleza claramente divergente por su carácter privado. Aquí quien decide el inicio y la finalización de las pesquisas y quien adopta la decisión de fondo es la propia em presa. Esta circunstancia se contrapone a aquellos otros casos de colaboración entre los particulares y el Estado (v. gr. informes brindados por las empresas a las autoridades estatales en el marco de una investigación judicial), en los que no obstante es el Estado, quien asume el dominio del proceso de "detection" y "reaction". Por ende, puede apreciarse que una primera característica saliente de las investigaciones internas es que un particular es quien detenta el "señorío" de la investigación ${ }^{6}$ y decide de forma autárquica y exclusiva según los intereses de la firma investigar o colaborar con la Justicia ${ }^{7}$.Vinculado también a ello surge que las sanciones adoptadas por la empresa en ningún caso representan una pena, por su falta de carácter

${ }^{3}$ KNAUER, K., Interne, cit. (n. 1), p. 42.

${ }^{4}$ ReEB, P., "Internal investigations". Neue Tendenzen privater Ermittlungen (Berlin, Duncker \& Humblot, 2011), pp. 1 s.

${ }^{5}$ Kindhäuser, U., Strafprozessrecht (2a edición, Baden-Baden, Nomos, 2006), $₫ 1$, núm. 9; Volk, K., Grundkurs StPO (7a edición, München, Beck, 2010), §3, núm. 1.

${ }^{6}$ Sobre el "principio del dominio" como elemento delimitador entre investigaciones privadas e investigaciones estatales mediante actores privados cfr. en detalle REEB, P., "Internal investigations", cit. (n. 4), pp. 8 ss.

${ }^{7}$ Ibíd., p. 48. 
público y de contenido estigmatizadora. Más bien, tanto las sanciones (v. gr. llamados de atención, rescisión contractual, reparación del daño, etc. $)^{8}$ como las restantes consecuencias (v. gr. programas de amnistía) $)^{9}$ de las que puedan ser pasibles los responsables de los ilícitos son materia del Derecho laboral y del Derecho civil.

A grandes rasgos puede decirse que el propósito central de las investigaciones empresariales es conocer la naturaleza y extensión de conductas incorrectas que acaecen dentro de un colectivo ${ }^{10}$, lo cual puede repercutir positivamente tanto respecto al Estado como a la empresa. Así, respecto al Estado las "internal investigations" le permiten penetrar en la intrincada estructura empresarial y además le ayudan a esclarecer conductas sospechosas, más eficientemente que lo que sería posible mediante la puesta en marcha de todo el aparato burocrático ${ }^{11}$. Por su parte, las empresas encuentran fuertes incentivos para realizar este tipo de pesquisas ${ }^{12}$ : en definitiva, el saneamiento de una empresa contribuye a mejorar su imagen en el mercado ${ }^{13}$, del mismo modo que puede ser un factor relevante para fundamentar la exclusión ${ }^{14} \mathrm{O}$ la atenuación ${ }^{15}$ de la responsabilidad penal. Incluso el caso "Siemens" ilustra bien cómo gracias a las investigaciones internas los elevados costos que

\footnotetext{
${ }^{8}$ En relación a estas concretas sanciones, véase: Maschmann, F., Vermeidung von Korruptionsrisiken aus Unternehmenssicht-Arbeits- und Zivilrecht, Corporate Governance-, en BENZ y otros (editores), Handbuch der Korruptionsprävention (München, Beck, 2007), núm. 154 ss. Desde una perspectiva general: Wauschkunn, A., Sanktionierung nach Abschluss der Untersuchungen, en Moosmayer, K. - Hartwig, N. (editores), Interne Untersuchungen. Praxisleitfaden für Unternehmen (München, Beck, 2012), p. 67 ss.

${ }^{9}$ Weisse, M., Ausgewählte arbeitsrechtliche Aspekte und Amnistie, en MoosmayER, K. - Hartwig, N. (editores), Interne Untersuchungen. Praxisleitfaden für Unternehmen (München, Beck, 2012), pp. 58 ss.; Pотіnecke, H. - Block, F., Gesellschaftliche Rabmenbedingungen und Beratung der Unternehmensführung, en KNIERIM, T. - RÜBenstahl, M. - TsambiKakis, M. (editores), "Internal investigations". Ermittlungen im Unternehmen (Heidelberg, Müller y otras, 2013), núm. 168 ss.

${ }^{10}$ Propper, E., Corporate Fraud Investigations and Compliance Programs (New York, Oceana Publications, 2000), pp. 52 s.

${ }^{11}$ McKendall, M. - De Marr, B. - Jones-Rikners, C., Ethical Compliance Programs and Corporate Illegality: Testing the Assumptions of the Corporate Sentencing Guidelines, en Journal of Business Ethics, 37 (2002), p. 369.

${ }^{12}$ Momsen, C., "Internal investigations" zwischen Mitwirkungspflicht und strafprozessuele Selbstbelastungsfreiheit, en ZIS., 6 (2011), p. 510.

${ }^{13}$ Nestler, N., "Internal", cit. (n. 2), núm. 29

${ }^{14}$ Como mostraré más adelante, ello puede ocurrir cuando la investigación empresarial permite mostrar que el delito no es consecuencia de un defecto de organización. Con todo, el traslado de esta última posibilidad al Derecho penal español parece algo discutible, ateniendo a la redacción del art. 31 bis CP.

${ }^{15}$ Cfr. entre otros, JAHN, M., Ermittlungen, cit. (n. 1), p. 41.
} 
supuso su realización se vieron ampliamente compensados por la rebaja de la sanción pecuniaria ${ }^{16}$.

Seguramente las anteriores circunstancias ayudan a explicar la notable expansión que vive este fenómeno en los últimos años en el plano académico y práctico. Especialmente en este último ámbito se evidencia cómo estas investigaciones ya dejan de ser un mecanismo propio de las grandes empresas. Al menos en Alemania, la realidad muestra que también empresas medianas (o hasta incluso pequeñas de hasta 100 miembros) comienzan a someterse a procesos de auto-limpieza.

Habiendo ubicado ya el problema de las “internal investigations" dentro de estas coordenadas me interesa ahora precisar el grupo de cuestiones que abordaré en este trabajo. Tratándose mi contribución de una introducción al fenómeno de las investigaciones internas empresariales, intentaré solamente diferenciarlas conceptualmente de otras prácticas similares que tienen lugar en el seno de la empresa. Junto a ello me ocuparé de la cuestión relativaa la obligatoriedad o no de su implementación, esto es, de la cuestión relativa a la existencia de un deber de indagar las sospechas de la comisión de un delito. Además, intentaré arrojar una lluvia de ideas sobre alguna de las cuestiones procesales más intrigantes y mostrar los caminos seguidos por la doctrina para explicar el traslado de las garantías procesales (especialmente en el ámbito de la obtención de prueba) a las investigaciones internas. En esta última parte me limitaré solamente a mostrar el sinnúmero de interrogantes que se abren con el mantenimiento de las reglas del debido proceso.

\section{NOCIONES BÁSICAS SOBRE INVESTIGACIONES INTERNAS}

\section{1. ¿Un fenómeno novedoso?}

Basta con echar un vistazo a la copiosa literatura en alemán aparecida en los últimos cinco años para formarse la idea de que las investigaciones internas son un fenómeno en notable expansión en el terreno del Derecho penal empresarial ${ }^{17}$. Es evidente que el auge de las "internal investigations"

${ }^{16}$ Gracias a la colaboración prestada por Siemens AC a las autoridades y a la realización de investigaciones internas, una multa inicial que se calculaba en varios miles de millones de euros, logró acordarse en alrededor de mil millones de euros ( $€ 395.000 .000$ acordados con la Fiscalía de Múnich y $€ 600.000 .000$ con la Securities and Exchange Commission y el Departamento de Justicia estadounidense).

${ }^{17}$ Además de los innumerables artículos de revista, en el último año y medio han aparecido voluminosos libros colectivos y monografías, cfr. KNIERIM, T. - RüBENSTahl, M. - Tsambikakis, M. (editores), "Internal investigations". Ermittlungen im Unternehmen (Heidelberg, Müller, 2013), passim; Moosmayer, K. - HaRTwig, N. (editores), Interne Untersuchungen. Praxisleitfaden für Unternehmen (München, Beck, 2012), passim.; Wewerka, F., "Internal investigations". Private Ermittlungen 
-como así también del "criminal compliance" en general- está ligado a las medidas adoptadas por los gobiernos de los Estados Unidos y de algunos miembros de la Unión Europea ${ }^{18}$ a partir de los escándalos derivados de los casos "Word-Com”, "Parmalat”, "Enron, Merck \& Company", "Riggs Bank" y "Siemens AG", entre otro" ${ }^{19}$. Las investigaciones internas no sólo han servido para identificar a los responsables de los ilícitos dentro de la empresa, sino también para muchos otros propósitos, entre otros, dar explicaciones al Estado y a la sociedad sobre negociones cuestionables; evidenciar el cumplimiento de requerimientos legales en materias vinculadas a la salud o al medio ambiente; influir en la estrategia empresarial, etc. ${ }^{20}$. Sin embargo, esta circunstancia no debería apresurarnos a afirmar que estamos ante un fenómeno totalmente novedoso a nivel global.

Si tomamos en consideración que las "internal investigations" no consisten exclusivamente en indagar sospechas de delitos, sino también de otras infracciones a la ley, podemos ya encontrar casos en los Estados Unidos durante la década de los 60', en los que los tribunales -a partir de la denuncia de la Security Exchange Comission (SEC) - ordenaban la instauración de procesos de auto-limpieza ${ }^{21}$. En el fondo, el desarrollo de este fenómeno se produje gracias a que la SEC comenzó a exigir que las empresas realizaran investigaciones internas con el objetivo de garantizar el cumplimiento de las leyes del Derecho cambiario ${ }^{22}$. Sin duda, esta tendencia se intensifica una década más tarde a raíz de las limitaciones materiales de la SEC para hacer frente a las grandes causas judiciales derivadas del escándalo de "Watergate"23.

im Spannungsfeld von strafprozessualen Grundsätzen und Anforderungen eines globalisierten Wirtschaftsstrafverfahrens; eine Problemanalyse unter besonderer Berücksichtigung des Falles Siemens (Frankfurt a. M. y otras, Peter Lang, 2012), passim; SpenL, S. - GrÜTZner, T., "Corporate Internal investigations" (München, Beck, 2012), passim; RÖDIGER, K., Strafverfolgung von Unternehmen, Internal investigations und strafrechtliche Verwertbarkeit von Mitarbeitergeständnissen (Frankfurt a. M., Peter Lang, 2012), passim; ReEB, P., "Internal investigations", cit. (n. 4), passim.

${ }^{18}$ Acerca de estas medidas véase, entre otros: Knauer, K., Interne, cit. (n. 1), pp. $43 \mathrm{~s}$.

${ }^{19}$ Sieber, U., Programas, cit. (n. 1), p. 206.

${ }^{20}$ Hemphill, T. - Cullari, F., Corporate Governance Practices: A Proposed Policy Incentive Regime to Facilitate internal investigationsand Self-Reporting of Criminal Activities, en Jounal of Business Ethics, 87 (2009), p. 334.

${ }^{21}$ Mathews, A., Internal Corporate Investigations, en Ohio St. L.J., 45 (1984), pp. $657 \mathrm{~s}$

${ }^{22}$ ReEB, P., "Internal investigations”, cit. (n. 4), p. 21.

${ }^{23}$ Estrada Cuadras, A. - Llobet Anglí, M., Derechos de los trabajadores y deberes del empresario: conflicto en las investigaciones empresariales internas, en SiLva Sánchez, J. (director), Criminalidad de empresa y "Compliance", Prevención y reacciones corporativas (Barcelona, Atelier, 2013), pp. 197 s. 
En este contexto la SEC apela a la cooperación de las empresas, no sólo mediante la presentación de informes, sino también mediante procesos internos de esclarecimiento de los hechos ${ }^{24}$. Además, es importante hacer notar que a comienzos de la década de los 70' las investigaciones internas ya están en boca de todos con motivo del esclarecimiento de sospechas de sobornos pagados por empresas norteamericanas a autoridades de Bélgica, Japón, Holanda, Honduras e Italia con el objetivo de obtener contratos públicos ${ }^{25}$. A mediados de los años 80 'se convirtieron en algo muy común en los Estados Unidos, hasta llegar al máximo de popularidad en todo el mundo con los escándalos financieros iniciados en el año $2001^{26}$. Incluso, un estudio realizado en 2010 por Michels da cuenta de que al año 2008 prácticamente la mitad de las sociedades de capital de los Estados Unidos realizan investigaciones internas ${ }^{27}$.

A partir de lo anterior, podría decirse resumidamente que el fenómeno de las "internal investigations" es una novedad especialmente en la familia jurídica continental, mientras que no así en los EE.UU. Esta circunstancia se ve claramente reflejada incluso en la literatura, dado que ya antes de los escándalos financieros de 2001 existen importantes contribuciones al tema en el mundo angloparlante, mientras que la abundante literatura en alemán recién aparece a partir del caso "Siemens" y en la actualidad vive uno de sus puntos más altos ${ }^{28}$. Por su parte, en la doctrina hispanoparlante el tema oscila entre la novedad y la ignorancia, puesto que prácticamente el tema no ha sido abordado.

\section{Delimitaciones conceptuales: investigaciones internas, medidas de control} y "cazas de brujas".

La primera cuestión que resulta importante analizar a partir de aquí es la relativa a la delimitación conceptual de las investigaciones internas para, a partir de ello, poder distinguirlas de otras medidas empresariales que presentan una estructura análoga, pero que cumplen cometidos diferentes. En términos generales podría decirse que una empresa "investiga" tanto cuando

${ }^{24}$ Mathews, A., Internal, cit. (n. 21), pp. 657 ss.

${ }^{25}$ Hemphill, T. - Cullari, F., Corporate, cit. (n. 20), p. 334; Mengel, A., $S$ 12: Arbeitsrechtliche Implementierung und Durchsetzung von Compliance-Systemen und Ethikregeln im Unternehmen, en HauschKa (editor), Corporate Compliance (2 edición, 2010), núm. 77. Para más detalles sobre los casos más renombradas de aquella época, véase: MATHEws, A., Internal, cit. (n. 21), pp, 658 ss.

${ }^{26}$ Hemphill, T. - Cullari, F., Corporate, cit. (n. 20), p. 334.

${ }^{27}$ Michels, K., Internal Corporate Investigations and the Truth, en Seton Hall Law Review, 40 (2010), pp. 84 ss.

${ }^{28}$ KNAUER, K., Interne, cit. (n. 1), p. 41. 
toma declaraciones a sus trabajadores o recurre a investigadores privados para indagar acerca de un presunto hecho de corrupción, como también cuando, por ejemplo, los propios auditores de la empresa revisan en su actividad cotidiana documentos contables. Igualmente si empleamos de un modo muy general la palabra "control", podríamos decir que las pesquisas realizadas por investigadores privados son medidas de control. Más aún, desde una perspectiva clásica del control de la criminalidad empresarial, las investigaciones internas desempeñan un papel importante ${ }^{29}$. Sin embargo, para entender con claridad el espectro de las investigaciones internas me parece fundamental distinguir en sentido estricto actividades de control y de investigación empresarial. Por esta razón, conviene distinguir ambas clases de actividades, sin perjuicio de los muchos puntos en contacto que pueden existir.

En ese sentido, es esencialmente de "control" la actividad cotidiana que realizan en una empresa, por ejemplo, los auditores dado que se encargan de revisar, examinar y evaluar los resultados de un determinado sector de gestión $^{30}$. De ahí la existencia de auditores de gestión contable, medioambiental, etc. Sin perjuicio de un mínimo componente "investigativo" que tienen estas actividades, ello no impide caracterizarlas como esencialmente de "control". Ahora bien, frente al "control empresarial" aparece la "investigación empresarial”. Ésta última es principalmente reactiva ${ }^{31}$, esto significa que recién se "enciende" esa competencia cuando existe la sospecha de que se ha cometido un ilícito o bien cuando la comisión del delito es bastante evidente y ya existe un proceso judicial en march $^{32}$. Por tanto, el perímetro conceptual de las investigaciones internas no abarca meras actividades de

\footnotetext{
${ }^{29}$ McKendall, M. - DeMarr, B. - Jones-Rikkers, C., Ethical, cit. (n. 11), p.
} 369.

${ }^{30}$ Sobre la noción de control en este terreno del "Corporate Governance”, véase, entre otros: De Cleyn, Compliance of Companies with Corporate Governance Codes: Case Study and Listed Belgian SMEs, en Journal of Business Systems, Governance and Ethics, 1 (2008), pp. 2 ss.

${ }^{31}$ SaHAN, O., Unternehmensinterne Untersuchungen aus rechtsanwaltlicher Perspektive, en Kuhlen, L. - Kudlich, H. - Ortiz de Urbina, I. (editores), Compliance und Strafrecht (Heidelberg y otras, Müller, 2012), p. 171; NeSTLER, N., Internal, cit. (n. 2), núm. 21; BüHRER, R., Einrichtungeiner internen Untersuchungsabteilung und deren Prozesse, en Moosmayer, K. - Hartwig, N. (editores), Interne Untersuchungen. Praxisleitfaden für Unternehmen (München, Beck, 2012), p. 101; KNAUER, K., Interne, cit. (n. 1), p. 42; REEB, “Internal Investigations", cit. (n. 4), p. 20. En cambio, entiende Propper, E., Corporate, cit. (n. 10), p. 53, que solamente tendrán una naturaleza reactiva aquellas investigaciones que se inician con motivo de una citación judicial de las autoridades estatales.

${ }^{32}$ De otra opinión, Estrada i Cuadras A. - Llobet Anglí, M., Derechos de los trabajadores, cit. (n. 23), pp. 201 s., quienes caracterizan como investigaciones in- 
control genérico, sino que comprende (al igual que el proceso penal) actividades destinadas a (intentar) "reconstruir el pasado" 33 y a adoptar medidas a partir de los hechos acreditados ${ }^{34}$.

Ayuda incluso a comprender más claramente la distinción entre tareas de control y de investigación prestar atención a la circunstancia de que las "internal investigations" sirven, entre otras cosas, para obtener información sobre deficiencias en el sistema de control interno de la empresa ${ }^{35}$.

Esta primera delimitación permite distinguir además investigaciones internas en sentido estricto de otras "investigaciones" (en sentido impropio), que podríamos caricaturizar como "cazas de brujas". Estos últimos son supuestos en los que la investigación que emprende el empleador no está destinada a corroborar o descartar la sospecha de un delito, sino que más bien representan medidas preventivas orientadas a proteger su patrimonio o controlar a sus empleados mediante la obtención de información personal. Así, por ejemplo, no podemos hablar de una investigación interna cuando el empresario contrata a un equipo de investigadores privados para que coloquen cámaras o grabadores de voz ocultos en lugares de reunión o de conversaciones de sus empleados, con el sólo objetivo de saber de la vida privada de los trabajadores o prevenir cualquier tipo de conspiración de ellos en contra del interés empresarial ${ }^{36}$.

ternas procesos preventivos, que en mi opinión deberían caracterizarsemás bien como de control.

${ }^{33}$ Ello no debe llevar a negar la clara interdependencia que existe entre las competencias empresariales de contralor e investigativas. De hecho, las sospechas que llevan a la implementación de las investigaciones internas surgen normalmente no sólo a partir de denuncias externas o del sistema de "Whistleblowing", sino también a partir de los informes presentados por los auditores. Esta delimitación tampoco niega cierto componente de contralor que en el fondo tienen las investigaciones internas, cfr. KNAUER, K., Interne, cit. (n. 1), p. 42.

${ }^{34}$ Es muy común encontrar un solapamiento de los conceptos de investigación y control en buena parte de la literatura norteamericana. Por ejemplo, cuando Propper, E., Corporate, cit. (n. 10), p. 9, advierte que en los últimos quince años el gobierno de los EE.UU. ha buscado fortalecer los incentivos para que las compañías adopten una actitud proactiva, en realidad no está aludiendo a las investigaciones internas sino a la instauración de programas de detección, prevención y monitoreo.

${ }^{35}$ Moosmayer, K., Compliance. Praxisleitfaden für Unternehmen (2a edición, München, Beck, 2011), pp. 95 ss.

${ }^{36}$ Un buen ejemplo de esto último lo ofrece el escándalo desatado en Alemania con motivo de las denuncias de espionaje que sufrían los trabajadores de las cadenas de supermercados Aldi, Lidl y Netto, entre otros. Aquí los dueños de los supermercados había instalado cámaras de video-vigilancia ocultas y contratado detectives privado para las tareas de espionaje y como resultado de ello la empresa pudo hacerse de importante información privada de sus trabajadores. 
Esta constelación que se denomina aquí “caza de brujas” está caracterizada por medidas empresariales que resultan ilegales per se. Ningún empresario puede alegar en su favor algún derecho con base legal o constitucional para acosar a sus trabajadores. Frente a ello, el empresario no sólo está habilitado a realizar investigaciones internas en virtud de su derecho de gestión y de protección de su patrimonio ${ }^{37}$, sino que además, en ciertos casos, puede hallarse obligado para evitar o reducir ciertos daños o peligros que amenazan a los trabajadores ${ }^{38}$. Sin duda, ciertas prácticas empresariales implementadas en las investigaciones puede encontrarse reñidas con la legalidad. Basta con tener presente, por ejemplo, la revelación de correspondencia (postal o electrónica) privada o el rastreo de las páginas visitadas por los trabajadores en horarios de trabajo, para advertir las desviaciones y abusos que pueden darse con motivo del proceso de auto-limpieza ${ }^{39}$. Sin embargo, estas desviaciones no hacen ilícitas a las investigaciones internas en sí mismas.

\section{Investigaciones internas pre-judiciales y para-judiciales.}

Entre las escasas contribuciones de la doctrina a la identificación de diferentes clases de investigaciones internas es posible destacar la existencia de dos grandes grupos ${ }^{40}$. Por un lado, existirían las investigaciones internas en sentido estricto y las investigaciones internas en sentido amplio, según participen en el esclarecimiento de los hechos solamente abogados externos o también miembros de la propia empresa, respectivamente. También, por otro lado, es posible distinguir según su carácter nacional y transnacional, según se trate de firmas locales o bien multinacionales. Sin embargo, al margen de las anteriores clasificaciones ${ }^{41}$, se destacan por su valor práctico dos grandes constelaciones de casos: investigaciones internas pre-judiciales y para-judiciales ${ }^{42}$.

En primer lugar, encontramos aquellas en las que las pesquisas empre-

${ }^{37}$ KnAUER, K., Interne, cit. (n. 1), pp. 46 s.

${ }^{38}$ Ley de Prevención de Riesgos Laborales (España), artículo 22; artículo 19 ET.

${ }^{39}$ En relación a los riesgos penales que surgen con motivo de las investigaciones empresariales cfr. Wy вITUL, T. - SCHUSTER, F., Datenschutzrechtliche und strafrechtliche Rahmenbedingungen der Ermittlungen, en KNIERIM, T. - RüBENSTAHL, M. - TSAMBIKAKIS, M. (editores), "Internal investigations". Ermittlungen im Unternehmen (Heidelberg, Müller, 2013), núm. 103 ss.; Montiel, Unternehmerische Selbstreinigung: Compliance-Programme, interne Untersuchungen und Neutralisierung strafrechtlicher Risiken, en Kuhlen, L. - Kudlich, H. - Ortiz de Urbina, I. (editores), Compliance und Strafrecht (Heidelberg, Müller, 2012), pp. 194 ss.

${ }^{40} \mathrm{Al}$ respecto, KNAUER, K., Interne, cit. (n. 1), p. 42.

${ }^{41}$ Respecto a ulteriores clasificaciones, véase: ESTRAda I CuAdras A. - LlobeT Anglí, M., Derechos de los trabajadores, cit. (n. 23), pp. 201 ss.

${ }^{42}$ Esta distinción es parcialmente coincidente con la acercada por SAHAN, O., Un- 
sariales se inician tan sólo a partir de meros indicios respecto a la comisión de un delito, sin que el hecho haya llegado todavía a los estrados judiciales. Denominaré estos casos investigaciones internas pre-judiciales. En segundo lugar, las investigaciones internas para-judiciales son aquellas en las que las pesquisas recién se inician como consecuencia de que un hecho o una red de comisión de ilicitudes es ventilado púbicamente en un proceso judicial. Seguramente este segundo grupo es el más conocido, dado que, por ejemplo, la macro investigación empresarial de Siemens se imbrica en este concepto. Además, buena parte de las medidas adoptadas a nivel internacional para promover las investigaciones internas tomaron principalmente como referente esta constelación, para de este modo facilitar el esclarecimiento de los hechos a partir de la colaboración de la empresa gracias a los posteriores auto-informes y otras modalidades de colaboración. Principalmente esta última clase de investigaciones tiene importantes repercusiones en la fijación del "culpability score".

Como entiende acertadamente Propper ${ }^{43}$, la amplitud del objeto de las indagaciones puede variar en uno y otro caso. Por lo general, las investigaciones pre-judiciales estarían enfocadas de un modo mucho más amplio que las para-judiciales, dado que en este segundo caso el proceso de esclarecimiento surgiría a partir de un reclamo de las autoridades judiciales, según el cual se solicita la investigación de un concreto hecho.

Ahora bien, que sean las investigaciones internas para-judiciales mucho más habituales y (por ende) más conocidas, no debe llevar a menospreciar la importancia de las de carácter pre-judicial. Cabe reparar que la realización de estas últimas cobra una importancia vital de cara a la determinación de la responsabilidad penal de la persona jurídica. Ello obedece a que ayudan a verificar si la sospecha o denuncia que se investiga constituye un ilícito aislado o si en verdad es un "out-put" de una red o sistema de corrupción que, con la venia de la cúpula directiva o por simple negligencia de ésta, se encuentra enquistada en la empresa. Por ejemplo, la denuncia del soborno de un trabajador de la empresa a un funcionario público extranjero puede versar sobre un hecho aislado que involucra solamente a ese trabajador y no a la empresa en su conjunto o, al contrario, puede ser el síntoma de una deficiente organización empresarial.

ternehmensinterne, cit. (n. 31), pp. 172 ss., entre investigaciones empresariales voluntarias e involuntarias.

${ }^{43}$ Propper, E., Corporate, cit. (n. 10), p. 53. 


\section{III. ¿EXISTE UN DEBER A REALIZAR INVESTIGACIONES INTERNAS?}

En el ámbito de la gestión empresarial la pregunta por la existencia de un deber de realizar una investigación interna resulta de gran relevancia a la hora de diseñar su estructura, como así también cuando se realiza una planificación de gastos de gestión ${ }^{44}$. Pero, además, desde un punto de vista jurídico resulta de un alto valor determinar si existe o no semejante deber y, en su caso, explicar dónde es que debe hallarse este deber de "auto-limpieza". Principalmente adquiere resonancia la cuestión a la hora de indagar por una posible de justificación de conductas empresariales que en el marco de estas pesquisas lesionan típicamente bienes jurídicos.

Esto especialmente se presenta respecto a las injerencias que realizan los investigadores en la intimidad de los trabajadores, especialmente mediante el acceso a sus ordenadores o a sus correos electrónicos o mediante la captación de imágenes por cámaras de video-vigilancia ${ }^{45}$. En cuanto a estas invasiones en la intimidad del trabajador resulta necesario distinguir diferentes esferas de protección. Existen ciertos supuestos en los que las intromisiones en la intimidad de los trabajadores acaban quedando al margen de la tipicidad ${ }^{46}$. En cambio, pueden constatarse injerencias en la intimidad que, por su gravedad - pero también por las particularidades de la relación laboral-, no pueden ser toleradas, incluso cuando el lesionado haya dado su consentimiento ${ }^{47}$. Así, por ejemplo, la captura de imágenes colocadas en baños o vestuarios, exámenes genéticos compulsivos, la interceptación de correspondencia electrónica estrictamente personal o el registro de taquillas implican la realización de las conductas de los artículos 197 ss. CPEsp. ${ }^{48}$. Sin embargo, también resulta plausible afirmar que el empresario tiene permitido en casos excepcionales realizar alguna de estas conductas siempre que se pretenda salvaguardar un

${ }^{44}$ Ibíd., p. 21.

${ }^{45}$ Schürrle, T. - Olbers, L., Praktische Hinweise zu Rechtsfragen bei eigenen Untersuchungen im Unternehmen, en CCZ., 5 (2010), p. 178; RÜBENSTAHL, M. - DebUs, S., Strafbarkeit verdachtsabhängiger E-Mail-und EDV-Kontrollen bei internal investigations? En NZWiSt., 4 (2012), pp. 129 ss.; REEB, “Internal Investigations”, cit. (n. 4), pp. 79 ss.

${ }^{46}$ Montiel, J., Unternehmerische, cit. (n. 39), pp. 195 ss.

${ }^{47}$ Sobre la problemática y las limitaciones de la eximente de consentimiento en las relaciones laborales, véanse: Momsen, C. Internal, cit. (n. 12), p. 512; BRÜssow, R. Petri, D., Arbeitsstrafrecht (München, Beck, 2008), núm. 217; Simitis, S., $\$ 4^{a}$, en EL MISMo (editor), Nomos Kommentar zum Bundesdatenschutzgesetz ( $7^{\text {a }}$ edición, BadenBaden, Nomos, 2011), núm. 62.

${ }^{48}$ Gómez Martín, V., Compliance und Arbeitnehmerrechte, en Kuhlen, L. - Kudilch, H. - Ortiz de Urbina, I. (editores), Compliance und Strafrecht (Heidelberg, Müller, 2012), p. 106. 
interés superior, como ser la seguridad de la empresa o de los trabajadores ${ }^{49}$. Aquí, siempre que se respete la dignidad del trabajador y se mantenga la proporcionalidad, sería posible reconocer una causa de justificación ${ }^{50}$. Sin embargo, la inaplicabilidad del estado de necesidad y de la legítima defensa (ante la falta de actualidad o inminencia de la agresión o peligro) ${ }^{51}$ conduce nuestras miradas directamente a la eximente del cumplimiento de un deber ${ }^{52}$. Por ello, surge aquí con tanta fuerza la pregunta por la existencia de un deber de realizar investigaciones internas y, por añadidura, la justificación de entrometerse de esta manera en la intimidad de los trabajadores.

Si tan sólo tomáramos como referencia las exigencias de un buen gobierno empresarial derivas de los "compliance programs" resulta lógico concluir que dicho deber existe. Las investigaciones internas son un componente fundamental para el mantenimiento de un sistema general de cumplimiento de la legalidad y para garantizar su verdadero seguimiento ${ }^{53}$. Ellas no sólo permiten disuadir a futuros transgresores de incurrir en conductas ilícitas, sino que también ayudan a detectar falencias en la organización empresarial y en el "compliance management" ${ }^{\text {". }}$. Así, para garantizar el buen funcionamiento de este "compliance management" es debido realizar investigaciones internas. Sin embargo, no resulta nada sencillo encontrar en la legislación alemana, estadounidense y española un deber legal que obligue a las empresas a someterse a un proceso de auto-limpieza.

La doctrina alemana ha realizado importantes esfuerzos en este sentido y como resultado de ello considera que este deber puede derivarse del $\S$

${ }^{49}$ Gómez Martín, V., Compliance, cit. (n. 48), pp. 115 ss.; Montiel, J. Unternehmerische, cit. (n. 39), pp. 200 ss.

${ }^{50}$ Romeo Casabona, Los delitos de descubrimiento y revelación de secretos. Especial consideración a su comisión en conexión con las nuevas tecnologias de la información y de la comunicación (Valencia, Tirant lo Blanch, 2004), p. 136; RodrígueZ-PiÑERO Bravo-Ferrer, M., Derecho a la intimidad y contrato de trabajo, en La Ley, 3 (2004), p. 1; Agustina Sanllehí, J., El delito de descubrimiento y revelación de secretos en su aplicación al control del correo electrónico del trabajador (Madrid, La Ley, 2009), pp. 176 y 178.

${ }^{51}$ En este sentido refiriéndose concretamente a la legítima defensa, WUTTKE, I., Straftäter im Betrieb (München, Herbert Utz, 2010), pp. 166 y 26; ReEB, "Internal Investigations", cit. (n. 4), p. 93. A otro resultado llegan Estrada i CuAdras A. Llobet Anglí, M., Derechos de los trabajadores, cit. (n. 23), pp. 224 ss., gracias a asimilar -en mi opinión de modo discutible- las investigaciones internas a las medidas preventivas de control.

${ }^{52}$ En detalle al respecto: Romeo Casabona, Los delitos, cit. (n. 50), pp. 131 ss.; Montiel, J. Unternehmerische, cit. (n. 39), pp. 204 ss.; Gómez Martín, V., Compliance, cit. (n. 48), pp. 118 ss.

${ }^{53}$ Hemphill, T. - Cullari, F., Corporate, cit. (n. 20), p. 335.

${ }^{54}$ Moosmayer, K., Compliance, cit. (n. 35), pp. 95 ss. 
130 OWiG. ${ }^{55}$. Por esta razón, también se llega a entender por parte de la doctrina alemana que el deber de investigación es en realidad una parte del cumplimiento de los deberes de supervisión en un sistema de "compliance" 56 . Sin embargo, esta fundamentación no resulta del todo convincente, sobre todo porque de este precepto tan sólo podría derivarse un deber de control o supervisión, pero no directamente un deber específico de investigar; es decir, habría un deber de "prevention", más no de "detection" la ausencia de un deber legal en Alemania ${ }^{58}$ obligaría a fundamentar la existencia de un deber de manera indirecta, a partir de la función de dirección de la empresa ${ }^{59}$.

Con problemas similares se tropieza en los EE.UU., donde de las actuales tendencias solamente puede inferirse un deber de control y de adopción de medidas preventivas ${ }^{60}$. Sin embargo, como se expuso más arriba las indagaciones empresariales no pueden ser asimiladas a las de control en sentido estricto. En definitiva, es posible concluir que tampoco en los EE.UU. existe un deber legal directo de realizar investigaciones internas ${ }^{61}$. Pese a ello, el sistema americano se ha diseñado de tal manera que las empresas que ponen en marcha procesos de auto-limpieza cuentan con incentivos tan importantes -rebaja de la pena o levantamiento de la acusación- que en el fondo las empresas están fácticamente compelidas a investigar ${ }^{62}$.

${ }^{55}$ HaRTwIG, N., Interne Untersuchungen in Unternehmen. Einführung und Überblick, en Moosmayer, K. - Hartwig, N. (editores), Interne Untersuchungen. Praxisleitfaden für Unternehmen (München, Beck, 2012), p. 8; SAHAN, O., Unternehmensinterne, cit. (n. 31), p. 174.

${ }^{56}$ Así, Hartwig, N., Pficht der Unternehmensleitung zur Durchführung interner Compliance Untersuchungen im Unternehmen und Konzern, en Moosmayer, K. Hartwig, N. (editores), Interne Untersuchungen. Praxisleitfaden für Unternehmen (München, Beck, 2012), p. 8.

${ }^{57}$ KNAUER, K., Interne, cit. (n. 1), p. 44.

${ }^{58}$ Así, BeHRens, "Internal Investigations": Hintergründe und Perspektiven anwaltlicher «Ermittlungen» in deutschen Unternehmen, en RIW., 1 (2009), p. 29. De todos modos no cabría descartar completamente la existencia de un deber legal de realizar las investigaciones empresariales, especialmente si se tiene en consideración la reforma de 2011 de la Ley alemana de Entidades Finacieras (KWG) en su $₫ 25$ c, Ap. 3, enunciado primero.

${ }^{59}$ KnAuer, K., Interne, cit. (n. 1), pp. 46 s.

${ }^{60}$ Propper, E., Corporate, cit. (n. 10), pp. 10 ss.

${ }^{61}$ ReEB, "Internal Investigations", cit. (n. 4), p. 21; DANN, M. - SCHмidt, K., Im Würgegriff der SEC?- Mitarbeiterbefragungen und die Selbsbelastung, en NJW., 25 (2009), p. 1851, aunque aludiendo a un deber general de cooperar con las autoridades.

${ }^{62}$ Se trataría en realidad más de una coerción fáctica que jurídica, cfr. KNAUER, K., Interne, cit. (n. 1), pp. 43 s.; ReEB, "Internal Investigations", cit. (n. 4), p. 24; DANN, M. - Schmidt, K., Im Würgegriff, cit. (n. 61), p. 1852. 
Por su parte, en el Derecho penal español tampoco resulta sencillo constatar la existencia de un deber de realizar investigaciones internas. El artículo 31 bis ap. $4^{\circ} \mathrm{CP}$. hace algunas referencias en sus letras b) y especialmente d), que aluden implícitamente a los efectos de las investigaciones internas en la determinación de la pena para la persona jurídica. Básicamente, el reporte empresarial de los resultados de las investigaciones a las autoridades judiciales y el descubrimiento de las actividades ilícitas cometidas por la empresa pueden tener incidencia para atenuar la pena. Sin embargo, parece desprenderse de aquí una facultad con la que cuenta la empresa para ver atenuada su responsabilidad penal, más no un deber de investigar, de modo que su no implementación tan sólo derivaría en la pérdida de un beneficio para la persona jurídica. Por consiguiente, también en España las empresas estarían compelidas sólo fácticamente a auto-sanearse, dado que de no aprovecharse los beneficios en la rebaja de la pena, una multa elevada podría poner seriamente en peligro la subsistencia de la persona jurídica. De ahí que podría hablarse impropiamente ${ }^{63}$ de la existencia de un deber fáctico ${ }^{64}$.

\section{Algunos desafíos de las InVESTigaciones internas EN SU ADECUACIÓN A LAS REGLAS DEL DEBIDO PROCESO}

\section{La problemática en torno a la "ordenanza procesal interna".}

En medio del notable auge de las investigaciones internas en las prácticas empresariales y en la atención doctrinal existe un dato práctico que llama poderosamente la atención. Pese a la notable importancia que tienen las investigaciones internas para mostrar que el sistema de programas de cumplimiento no es una mera "fachada", son muy pocas las empresas que se han

${ }^{63}$ Impropiamente, por cuanto la conducta de realizar investigaciones internas no estaría calificada deónticamente como obligatoria por el Derecho penal español.

${ }^{64}$ Desde luego que esta circunstancia abriría interrogantes sobre la aplicabilidad de la eximente del ejercicio legítimo de un deber. De todos modos, entiendo que estas dudas no pueden ser concluyentes, toda vez que la jurisprudencia del Tribunal Supremo no deja en claro si el deber debe surgir de una ley, ni menos aún, de una ley penal. Véanse las sentencias del Tribunal Supremo N 277 - 2004, Sala de lo Penal, de 5 marzo; No 601 - 2003, Sala de lo Penal, de 25 abril; No 1810 - 2002, Sala de lo Penal, de 5 noviembre; $N^{\circ} 1601$ - 2002, Sala de lo Penal, de 30 septiembre; $N^{\circ} 2466$ - 2001, Sala de lo Penal, de 24 diciembre; $N^{\circ} 871$ - 1998, Sala de lo Penal, de 19 junio. Así no quedaría excluida la posibilidad de derivar este deber indirectamente del Derecho societario, como lo hace parte de la doctrina en Alemania. Sobre esto último: Potinecke, H. BLOCK, F., Gesellschaftliche Rahmenbedingungen und Beratung der Unternehmensführung, en Knierim, T. - Rübenstahl, M. - Tsambikakis, M. (editores), "Internal Investigations”. Ermittlungen im Unternehmen (Heidelberg, Müller, 2013), núm. 4 ss. 
autorregulado en esta materia ${ }^{65}$. Dicho de otra manera: son muy escasos los supuestos en los que las empresas se han auto-regulado, estableciendo las pautas que guían las investigaciones internas, esto es, normas que, por ejemplo, regulan las diferentes fases de la investigación, la extensión de las facultades investigativas del empresario o su representante, las condiciones de los interrogatorios, la extensión de los deberes de información de los interrogados, etc. Por todo ello una autorregulación en esta materia resulta fundamental para cumplir con los cometidos del "compliance"66.

Por un lado, la existencia de reglas escritas resulta beneficiosa para el empresario, en cuanto puede ahorrarle los "dolores de cabeza” económicos y jurídicos que muchas veces trae la improvisación. Pero no solamente para el empresario. También la existencia de una "autorregulación procesal interna" puede garantizar, frente al trabajador, la previsibilidad de la actuación del empleador y el principio de buena fe contractual ${ }^{67}$. Dicho con otros términos: el establecimiento de un código procedimental contribuye significativamente a garantizar la transparencia de las prácticas, del mismo modo que permite delinear con claridad los roles que asumirá cada parte en la investigación. Todo ello haría pensar que no sólo resulta conveniente una autorregulación, sino que incluso, ello debería ser obligatorio, sobre todo si se tiene en cuenta la relevancia de las investigaciones internas en el sistema de "compliance management" 68 .

Con todo, la dificultad más importante que se presenta con la creación de una autorregulación en materia de investigaciones internas tiene que ver con la multidimensional dad de aspectos jurídicos y no jurídicos que se ven envueltos $^{69}$. El problema no radica tanto en la variedad de cuestiones a las que se debe atender como en lo difícil que resulta compatibilizar las exigencias procedentes de todas estas dimensiones. Por ejemplo, la necesaria consideración máximas procesales (como puede ser el principio "nemo tenetur se ipsum

${ }^{65}$ Momsen, C. - Grützner, T., Verfahrensregeln für interne Ermittlungen. Kritische Würdigung der Thesen der BRAK zum Unternehmensanwalt im Strafrecht, en DB., 32 (2011), pp. 1794 y 1798.

${ }^{66}$ Abogando por la auto-regulación empresarial en esta materia: NiETo MARTín, A., Grundlagende Probleme von Compliance und Strafrecht, en KuHLEn, L. - Kudlich, H. - Ortiz de Urbina, I. (editores), Compliance und Strafrecht (Heidelberg, Müller, 2012), pp. 53 ss.; BüHRER, R., Einrichtung, cit. (n. 31), p. 109.

${ }^{67}$ Knierim, T., Erfordernisse, cit. (n. 1), p. 84; Schürrle, T. - Olbers, L., Praktische, cit. (n. 45), p. 179.

${ }^{68}$ Así, Momsen, C. - Grützner, T., Verfahrensregeln, cit. (n. 65), pp. 1794 y 1798, consideran existente este deber en la Ley de sociedades de capital y en el $₫ 130$ OWiG.

${ }^{69}$ Propper, E., Corporate, cit. (n. 10), p. 54. 
accusare") puede traer significativos problemas para la relación laboral que une al empresario y al trabajador y que se rige por el Derecho privado ${ }^{70}$.

Aquí me interesa simplemente acercar dos criterios generales que puede guiar el diseño general de una "ordenanza procesal interna". El primero versa sobre la necesidad de que estas reglas escritas reflejen verdaderamente los intereses de las partes y, en especial, del trabajador ${ }^{71}$. Ello favorecería el equilibrio de poderes en la relación laboral ${ }^{72}$, al igual que haría más viable el terreno para que los trabajadores se comprometan con el proceso de autolimpieza ${ }^{73}$. Por su parte, el segundo criterio apunta a garantizar las reglas del debido proceso. Esto último resulta de enorme complejidad dado que esta garantía parece ubicarse en este contexto en una posición intermedia, en la que no resulta totalmente excluida (pese a ser las investigaciones internas un proceso regida principalmente por el Derecho privado), pero tampoco aplicable en toda su extensión (pese a las importantes similitudes con el proceso penal y a que puedan ponerse en peligro durante la investigación derechos fundamentales de los trabajadores). En este contexto, el gran desafío es repensar para las investigaciones internas un sistema de garantías de rigor intermedio ${ }^{74}$.

\section{Niveles de sospech a necesarios para iniciar investigaciones en la empresa.}

La decisión empresarial sobre el sí y el cómo de una investigación no está exenta de riesgos y condicionamientos. Por un lado, existe un claro condicionante económico: las investigaciones internas suponen elevados costos y por esa razón no cualquier empresa está en condiciones de hacer frente a ellos $^{75}$. Muchas veces sucede que algunas firmas se ven obligadas por motivos

${ }^{70}$ Momsen, C. - Grützner, T., Verfahrensregeln, cit. (n. 65), p. 1793.

${ }^{71}$ Sobre los diferentes sentidos en los que puede incorporarse al trabajador en el diseño e implementación de estas autoregulaciones, cfr. Montiel, J. Unternehmerische, cit. (n. 39), pp. 191 ss.

${ }^{72}$ LANDA ZAPIRAIN, J., Ética empresarial y responsabilidad social corporativa, en GoÑ SEIN (director), Ética empresarial y códigos de conducta (Madrid, La Ley, 2011), pp. 145 ss.

${ }^{73}$ Sin duda este último aspecto depende en gran medida de los valores fijados en los Códigos de ética empresariales y del modo en que la empresa logra inculcar y transmitirlos. Al respecto, Bock, D., Criminal Compliance (Baden-Baden, Nomos, 2011), p. 730.

${ }^{74}$ A favor de esta perspectiva intermedia: SzESNY, A., Im Blickpunkt: internal investigations. Zulässigkeit und Grenzen unternehmensinterner Ermittlungen, en BB., 45 (2011), p. vii; Grimm, D. - FreH, F., Mitarbeiterbefragungen und Mitwirkung des Betriebsrats, en $K S z W ., 1$ (2012), p. 91.

${ }^{75}$ Sahan, O., Unternehmensinterne, cit. (n. 31), pp. 174 ss. El caso "Siemens" es un excelente ejemplo de ello: las investigaciones le costaron a la empresa cerca de mil millones de euros [véase: KuHLEn, Grundfragen von Compliance und Strafrecht, en 
económicos a tener pretensiones mucho más modestas a la hora de investigar la sospecha de un delito. En las mismas coordenadas debe resaltarse también que el inicio de una investigación no es un hecho que pase inadvertido para los accionistas: una pesquisa mal realizada (por exceso o por defecto) puede también incidir negativamente en el valor de las acciones de la empresa ${ }^{76}$. Por otro lado, prácticas demasiado intrusivas de los investigadores puede generar responsabilidad en la empresa por infracciones penales, laborales y del Derecho de protección de datos ${ }^{77}$. Todas estas razones sirven para entender que la decisión de dar inicio a una investigación surge de una complicada ponderación de factores con incidencia jurídica y económica ${ }^{78}$.

Ahora bien, junto a estos motivos aparece un factor que complejiza aún más el panorama de cualquier corporación. La fuerte presión que reciben las empresas para adecuarse a las exigencias generales del "compliance management" y especialmente evitar incurrir en responsabilidad jurídica (aunque penal específicamente) llevan a los órganos de gobierno a no esperar a "tener el agua al cuello". Más bien, deben a evitar o disminuir al mínimo los costos jurídicos y de reputación, mediante investigaciones que se inicien apenas se cuenta con un mínimo de sospecha ${ }^{79}$. Ello viene a significar que a la empresa se le exige no sólo una decisión materialmente acertada (que considere las anteriores cuestiones jurídicas y económicas) sino también veloz. De esta manera la empresa se ve ante una encrucijada de la que difícilmente pueda salir completamente ilesa.

La exigencia de celeridad en el inicio de las investigaciones conduce a cuestionar una idea que, sin embargo, intuitivamente resulta plausible: el nivel de sospecha requerido para iniciar las investigaciones debería ser superior al

Kuhlen, L. - Kudlich, H. - Ortiz de Urbina, I. (editores), Compliance und Strafrecht (Heidelberg, Müller, 2012), pp. 9 ss.] e incluso ya para 2008 la empresa alemana gastó $€ 63.000 .000$ entre la contratación de asesores externos para que realicen las investigaciones internas y medidas para evitar fallas del sistema de control. Véase el informe de Siemens de 26 de abril de 2007 en http: - - www.siemens.com - investor pool - de - investor_relations - finanzpublikationen - reden_prasentationen - 2007-0426_legalproceedings_1445770.pdf (consultado el 10 de marzo de 2013). Analizando en la doctrina este punto MoMSEN, C. Internal, cit. (n. 12), p. 510.

${ }^{76}$ Propper, E., Corporate, cit. (n. 10), pp. 58 ss.

${ }^{77}$ Véase el Dictamen de la BRAK N 35 - 2010, p. 7. Cfr. también: SCHÜRRLE, T. - Olbers, L., Praktische, cit. (n. 45), p. 179; SzeSny, A., Im Blickpunkt, cit. (n. 74), p. vi; Gerke, B. - Richter, M., Die Vertretung von Arbeitsgebern in (Arbeits-) Strafverfahren, en Gerke, B. - KRAfT, O. - Richter, M., Arbeitsstrafrecht. Strafrechtliche Risiken und Risikomanagement (Heidelberg, Müller, 2012), núm. 104.

${ }^{78}$ Pickett, S., "Internal Investigations": A Basic Guide Anyone Can Use (Southern Gate, Wiley, 2008), p. 27.

${ }^{79}$ Propper, E., Corporate, cit. (n. 10), pp. 10 ss.; Sahan, O., Unternehmensinterne, cit. (n. 31), p. 175 . 
de un proceso judicial ordinario. En mi opinión, esta intuición se apoyaría en que en un Estado de Derecho las facultades coercitivas e investigativas de la empresa deben ser menores a las de las autoridades públicas, quienes sí detentan la legitimidad política para ello. No obstante, si se toma en serio y sin cinismo cuál es la función que el mismo Estado quiere asignarle al empresario a la hora de prevenir delitos, no resulta disparatado permitir al menos que las investigaciones puedan realizarse cuando se cuenta con los mismos niveles de sospecha que se aceptan para iniciar una investigación judicial ${ }^{80}$. Tanto a nivel nacional como internacional las empresas se ven compelidas (fácticamente) a colaborar con las autoridades y a convertirse, en el fondo, en el "brazo extendido" de la justicia en la empresa. Mantener la intuición inicial colocaría al empresario en una situación de cuasi-inexigibilidad.

Además, que una empresa ponga en marcha un mecanismo de "autolimpieza” no significa que necesariamente tendrá lugar un proceso investigativo con dimensiones idénticas o equiparables a las de un proceso penal. Antes de todo inicio de una investigación la junta directiva debe analizar la oportunidad y las medidas que serán adoptadas, de conformidad con la envergadura del problema ${ }^{81}$. La sola idea de proporcionalidad es seguida en general en el ámbito de las investigaciones internas ${ }^{82}$ y por esa razón las medidas adoptadas siempre están sujetas a la gravedad del delito sospechado, pero sobre todo a la credibilidad o certeza que existe respecto a la sospecha ${ }^{83}$. Ello significa, por ejemplo, que el simple "rumor de pasillo" respecto a que un empleado sobornó a un funcionario público no conlleva automáticamente que el empresario disponga una revisión generalizada de correos electrónicos personales y laborales, de taquillas, etc. ${ }^{84}$. Para estos casos quizá resulta más adecuado la adopción de otras medidas menos invasivas ${ }^{85}$.Más bien, sería esperable que la empresa decida iniciar una investigación cuando, a partir de suficientes y fundadas sospechas, esté en condiciones de concluir que existe la probabilidad, según leyes de la experiencia, de que el delito ha tenido lugar ${ }^{86}$. En definitiva, iniciar una investigación empresarial apenas

\footnotetext{
${ }^{80}$ En este sentido: Momsen, C. - Grützner, T., Verfahrensregeln, cit. (n. 65), p. 1793.

${ }^{81}$ Propper, E., Corporate, cit. (n. 10), pp. 51 ss.

${ }^{82}$ Momsen, C. - Grützner, T., Verfahrensregeln, cit. (n. 65), pp. 1793 ss.

${ }^{83}$ Pauthner-Seidel - Stephan,J., \& 27: Compliance-Managementsysteme für Unternehmensrisiken im Bereich des Wirtschaftsstrafrechts, en HauschKa (editor), Corporate Compliance (2a edición, München, Beck, 2010 ), núm. 50.

${ }^{84}$ Buchert, R. - Jасов-Hofbauer C., Hinweisgebersysteme des Unternehmens, en Knierim, T. - Rübenstahl, M. - Tsambikakis, M. (editores), "Internal Investigations”. Ermittlungen im Unternehmen (Heidelberg, Müller, 2013), núm. 39.

${ }^{85}$ Momsen, C. - Grützner, T., Verfahrensregeln, cit. (n. 65), pp. 1793 ss.

${ }^{86}$ SaHAn, O., Unternehmensinterne, cit. (n. 31), p. 174. Sobre los conceptos de
} 
se recibe una denuncia o se toma conocimiento de un rumor no representa necesariamente una medida ilegítima o desproporcionada. Ahora bien, solamente puede disponer la junta directiva la realización de una investigación corporativa cuando como mínimo existe una sospecha fiable de que se ha cometido un ilícito ${ }^{87}$.

3. Apuntes sobre la problemática del principio "nemo tenetur se ipsum accusare" y del uso de la prueba en el proceso penal.

Una de las cuestiones más seriamente debatidas de la implementación de investigaciones en la empresa surge con motivo de posibles afectaciones al principio "nemo tenetur se ipsum accusare" ". Básicamente, se pone el tela de juicio que el trabajador tenga el deber de informar o de ofrecer documentación a los abogados empresariales, pudiendo ser este información utilizada posteriormente en su contra. La dificultad de la problemática estriba en que estamos en un ámbito de intersección del Derecho privado y del Derecho público, en el que no pueden evitarse rispideces entre las garantías que rigen a ambos lados. Un traslado de las garantías del proceso penal a las investigaciones internas podría generar notables interferencias y deformaciones en las relaciones jurídicas amparadas por el Derecho laboral, especialmente porque el trabajador podría incumplir deberes legales o contractuales bajo el amparo de la garantía del principio "nemo tenetur nemo tenetur se ipsum accusare" ${ }^{89}$. Además, en sentido contrario, resulta dudoso según los pará-

sospecha y de probabilidad necesarios para el inicio de una investigación judicial (aplicable, según lo visto, al comienzo de las investigaciones empresariales), cfr. KÜHNE, Strafprozessrecht. Eine systematische Darstellung des deutschen und europäischen Strafverfahrensrechts ( $8^{a}$ edición, Heidelberg, Müller, 2010), núm. 327 ss.

${ }^{87}$ Por esta razón encuentro conceptualmente discutible que puedan existir (como tales) investigaciones internas en las que no haga falta contar con una sospecha. Considerando posible distinguir entre investigaciones empresariales que exigen sospechas y otras que no, Estrada i Cuadras A. - Llobet Anglí, M., Derechos de los trabajadores, cit. (n. 23), p. 201. Es más, como entiende correctamente KüHNE, Strafprozessrecht, cit. (n. 86), núm. 336, resulta conceptualmente insostenible hablar de una investigación sin sospecha.

${ }^{88}$ Basta simplemente con echar un vistazo a la copiosa literatura alemana sobre investigaciones internas que se aboca casi con exclusividad a esta cuestión, véase: Roxin, I., Probleme und Strategien der Compliance-Begleitung inUnternebmen, en StV., 2 (2012), pp. 120 ss.; Bittmann, F. - Molkenbur, J., Private Ermittlungen, arbeitsrechtliche Aussagepflichtund strafprozessuales Schweigerecht, en Wistra. Zeitschrift für Wirtschaft und Steuerstraftrechtwistra, 10 (2009), pp. 377 ss.; JAHN, M., Ermittlungen, cit. (n. 1), p. 43; Knauer, C. - Buhlmann, E., Grenzen der strafprozessualen Verwertbarkeitunternehmensinterner Ermittlungen, en AnwBl. (2010), pp. 389 ss.; RöDIGER, K., Strafverfolgung, cit. (n. 17), pp. 258 ss.

${ }^{89}$ Bittmann, F. - Molkenbur, J., Private, cit. (n. 88), p. 376; Schürrle, T. Olbers, L., Praktische, cit. (n. 45), p. 178. 
metros del Estado de Derecho hacer totalmente inaplicables garantías del debido proceso. Estas dificultades han dado lugar incluso a un importante dictamen de la Bundesrechtsanwaltskammer (BRAK) sobre los abogados empresariales en cuestiones penales, en el que intenta ofrecer un camino conciliatorio entre las exigencias provenientes del Derecho privado y del Derecho procesal penal ${ }^{90}$.

Ahora bien, en esta discusión se ven envueltas diferentes cuestiones que, en mi opinión, convendría deslindar del modo más claro posible. Por un lado, aparece la cuestión vinculada a si el trabajador es libre o no de declarar frente a los investigadores (cuestión de la existencia de un deber de informar o declarar), mientras que, por el otro, surge el problema del empleo que se hace de la prueba obtenida mediante la declaración del trabajador (cuestión de la utilización de la prueba).

No es infrecuente que al estudiar el fenómeno de la privatización de la lucha contra la criminalidad se acabe asimilando indebidamente las investigaciones internas al proceso pena ${ }^{91}$. Si bien es cierto que aquí se habla de investigaciones de hechos criminales, ellas no dejan de ser un fenómeno regido por el Derecho privado, dado que quien realiza la pesquisa carece de la potestas estatal y solamente se ve amparado por los derechos concedidos por el ordenamiento laboral ${ }^{92}$. Estas pesquisas continúan siendo una faceta de la relación laboral cada día más frecuente. Tratándose entonces las investigaciones internas de un proceso que no es ni estatal ni de naturaleza represiva no parece adecuado reconocerle al trabajador una libertad de declaración ${ }^{93}$, a partir de concebir el principio "nemo tenetur" como una axioma válido en todo el Derecho ${ }^{94}$. Por esta razón, en la medida en que existe un deber legal o contractual del trabajador de brindar información a su empleador ${ }^{95}$, los abogados de la empresa podrán interrogar a los trabajadores, siempre

${ }^{90}$ Dictamen de la BRAK N ${ }^{\circ} 35$ - 2010, pp. 10 ss.

${ }^{91}$ KNAUER, K., Interne, cit. (n. 1), pp. 47 ss.

${ }^{92} \mathrm{RoTsch}$, Criminal Compliance in Theorie und Praxis des Wirtschaftsstrafrechts (manuscrito inédito).

${ }^{93}$ Sin embargo, Kuhlen, Grundfragen, cit. (n. 74), p. 22, expresa sus dudas respecto a si semejante toma de postura es correcta, dado que si se interpretara que mediante las investigaciones se produce una tercerización de la persecusión penal se impone la pregunta acerca de por qué entonces no rigen para la empresa las regulaciones del StPO.

${ }^{94}$ Schumr, J. Vorbemerkung zu den 58133 ff, en Knauer, C. - Kudlich, H. SchneIder, H. (editores), Münchener Kommentar StPO, núm. 103 (en prensa); REEB, "Internal Investigations", cit. (n. 4), p. 122. De otro opinión, entre otros: MoMSEN, C., Internal, cit. (n. 12), p. 516.

${ }^{95}$ JAHN, M., Ermittlungen, cit. (n. 1), p. 44. En Alemania estos deberes se derivarían directamente del $₫ 666$ BGB e indirectamente de los $\$ \$ 611,241$ II y 242 BGB, que se 
que se les garantice información fiable, la asistencia técnica-letrada, etc. ${ }^{96}$. Además, diferentes normas legales sustentan el derecho del empresario a obtener información laboral, como así también deberes de colaboración o investigación, incluso respecto a daños causados a la empresa por el propio declarante ${ }^{97}$. Esta restricción a la libertad de declarar evita, en definitiva, una desnaturalización de la relación laboral ${ }^{98}$.

Sin embargo, la inaplicación de la garantía en cuestión no significa que cualquier práctica destinada a obtener material probatorio sea lícita. Aquí resulta válida la Tesis $N^{\circ} 3$ del Dictamen de la Comisión de Derecho Penal de la Bundesrechtsanwaltkammer"9 ${ }^{99}$ según la cual los investigadores deberían sujetarse a las leyes generales y a los estándares del Estado de Derecho, de tal modo que, en concreto, no serían lícitas aquellas pruebas obtenidas en la investigación interna mediante engaño o violencia ${ }^{100}$.

Junto a la cuestión de la existencia del deber jurídico-laboral de informar -léase también derecho jurídico-laboral de obtener información-, aparece la relativa al empleo de esa información. Dado que las investigaciones internas son materia de regulación del Derecho laboral y además que el principio "nemo tenetur" no rige en esta rama jurídica, no parecen presentarse inconvenientes para emplear la información obtenida por los abogados a la hora de adoptar decisiones principalmente laborales; esto es, para adoptar la decisión que pone punto final a las investigaciones. Ahora bien, cuando en cambio esa información quiere ser empleada como prueba en el proceso penal este criterio ya deja de ser válido. Dado que aquí sí estamos ante un proceso estatal de carácter represivo, toda aquella información incriminatoria obtenida en las investigaciones internasen vulneración del "nemo tenetur" no podrá ser empleada ${ }^{101}$. No obstante, esta última precisión abre un nuevo frente de problemas para la empresa. En efecto, puede suceder, por ejemplo, que se comprobase la comisión de un delito de corrupción aislado gracias a la información aportada por su autor en virtud de un deber legal, que

corresponde con la buena fe laboral, cfr. DANn, M. - Schмidt, K., Im Würgegriff, cit. (n. 61), p. 1852.

${ }^{96}$ Sobre las condiciones de estos interrogatorios, ver, por todos: BRAK-Stellungnahme. $\mathrm{N}^{\circ} 35$ - 2010, p. 11.

${ }^{97}$ Schürrle, T. - Olbers, L., Praktische, cit. (n. 45), p. 178; Bittmann, F. - MoLKenbur, J., Private, cit. (n. 88), p. 376.

${ }^{98}$ Momsen, C. - Grützner, T., Verfahrensregeln, cit. (n. 65), p. 1793.

${ }^{99}$ Dictamen de la BRAK N 35 - 2010, pp. 9 ss.

${ }^{100}$ En el caso alemán implicaría la vigencia del $\$ 136$ a StPO. en el marco de las investigaciones internas, cfr. SZESNY, A., Im Blickpunkt, cit. (n. 74), p. vii; 74, D. - FrEH, F., Mitarbeiterbefragungen, cit. (n. 74), p. 91; SchuнR, J., Vorbemerkung, cit. (n. 94), núm. 117.

${ }^{101}$ SCHUHR, J., Vorbemerkung, cit. (n. 94), núm. 115. 
des-incrimina a la empresa. Esta situación podría complicar notablemente la posición de la persona jurídica en el proceso, por lo que resulta necesario indagar sobre las posibles soluciones al problema en este punto ${ }^{102}$.

\section{REFLEXIONES FINALES}

Pocos fenómenos jurídicos como las investigaciones internas ofrecen en la actualidad un terreno tan rico y próspero para un trabajo científico interdisciplinario. Como pudo verse, los procesos de saneamiento empresarial tocan puntos centrales del Derecho penal, al igual que del Derecho laboral, del Derecho de protección de datos, del Derecho societario, etc. Pero no sólo es una temática que incumbe exclusivamente a la ciencia jurídica, sino que claramente la ciencia de la Administración tiene mucho por aportar a este terreno. Desde luego que cualquier objeto de investigación puede ser susceptible de un abordaje interdisciplinario, pero la particularidad central de nuestro tema es que incluso los abordajes jurídico-penales no pueden dejar de lado cuestiones procedentes de otros terrenos del Derecho y de la Administración. Ignorar estos otros factores limitaría notablemente la capacidad de rendimiento de cualquier contribución al tema. En semejante contexto se ven aún más claramente las modestas pretensiones de esta contribución. En el fondo tan sólo se ha buscado acercar a la discusión en castellano algunos de los debates actualmente más relevantes en otros países y además formular algunas delimitaciones conceptuales necesarias para comprender debidamente el significado de las investigaciones internas.

Tanto en Iberoamérica como en el resto de Europa todavía queda mucho por hacer en esta materia a nivel doctrinal, empresarial y gubernamental. Me animo a aventurar que en los próximos años las investigaciones internas ocuparán el centro de los debates académicos en la ciencia jurídica, como una derivación de la actual "euforia" desatada por el "compliance". Más importante, empero, es que las empresas y el Estado sean conscientes de la relevancia del tema y a partir de ello adopten medidas en esta dirección. Como enfaticé ya páginas atrás, resulta imperioso que las empresas se autoregulen en esta materia, para reducir así los innumerables riegos jurídicos que penden ante la realización de toda investigación. También el Estado debe tomar cartas en el asunto y acomodar su legislación a las particularidades de estos procesos de limpieza empresarial. Hasta ahora se ha observado una actitud un tanto cínica del Estado, puesto que, por un lado, compele

${ }^{102} \mathrm{Al}$ respecto, cabe destacar la propuesta acercada por SCHUHR, J. Vorbemerkung, cit. (n. 94), núm. 116, consistente en hacer aplicable para este caso la "hypothetical clean path doctrine", según la cual se aceptan aquellos medios de prueba que aún sin la declaración del imputado podrían realmente ser obtenidas con alta probabilidad. 
fácticamente a las empresas a realizar investigaciones internas, pero, por otro lado, las obsoletas pautas jurídicas que quieren hacerse valer exponen a los empresarios a altos riesgos jurídicos y económicos. Dicho con otras palabras: pareciera que se fomentan las investigaciones internas, pero una vez que se obtuvo la información querida se lo abandona al empresario a su suerte cuando surgen dudas sobre la compatibilidad de sus prácticas con la desactualizada legislación.

\section{BiBLIOGRAFÍA}

Agustina Sanllehí, J., El delito de descubrimiento y revelación de secretos en su aplicación al control del correo electrónico del trabajador (Madrid, La Ley, 2009).

BEHRENS, "Internal Investigations": Hintergründe und Perspektiven anwaltlicher «Ermittlungen» in deutschen Unternehmen, en RIW., 1 (2009).

Bittmann, F. - Molkenbur, J., Private Ermittlungen, arbeitsrechtliche Aussagepflichtund strafprozessuales Schweigerecht, en Wistra. Zeitschrift für Wirtschaft und Steuerstraftrechtwistra, 10 (2009).

Bock, D., Criminal Compliance (Baden-Baden, Nomos, 2011).

BRÜssow, R. - Petri, D., Arbeitsstrafrecht (München, Beck, 2008).

Buchert, R. - Jaсов-Hofbauer C., Hinweisgebersysteme des Unternehmens, en Knierim, T. - Rübenstahl, M. - Tsambikakis, M. (editores), “Internal Investigations”. Ermittlungen im Unternehmen (Heidelberg, Müller, 2013).

BüHRER, R., Einrichtungeiner internen Untersuchungsabteilung und deren Prozesse, en Moosmayer, K. - Hartwig, N. (editores), Interne Untersuchungen. Praxisleitfaden für Unternehmen (München, Beck, 2012).

Dann, M. - Schmidt, K., Im Würgegriff der SEC?-Mitarbeiterbefragungen und die Selbsbelastung, en NJW., 25 (2009).

De Cleyn, Compliance of Companies with Corporate Governance Codes: Case Study and Listed Belgian SMEs, en Journal of Business Systems, Governance and Ethics, 1 (2008),

Estrada Cuadras, A. - Llobet Anglí, M., Derechos de los trabajadores y deberes del empresario: conflicto en las investigaciones empresariales internas, en SILVA SÁNCHEZ, J. (director), Criminalidad de empresa y "Compliance", Prevención y reacciones corporativas (Barcelona, Atelier, 2013).

Gerke, B. - Richter, M., Die Vertretung von Arbeitsgebern in (Arbeits-) Strafverfahren, en Gerke, B. - Kraft, O. - Richter, M., Arbeitsstrafrecht. Strafrechtliche Risiken und Risikomanagement (Heidelberg, Müller, 2012).

Gómez Martín, V., Compliance und Arbeitnehmerrechte, en Kuhlen, L. - Kudlich, H. - Ortiz de Urbina, I. (editores), Compliance und Strafrecht (Heidelberg, Müller, 2012).

Grimm, D. - Fren, F., Mitarbeiterbefragungen und Mitwirkung des Betriebsrats, en $K S z W ., 1$ (2012).

HaRTwig, N., Interne Untersuchungen in Unternehmen. Einführung und Überblick, en Moosmayer, K. - Hartwig, N. (editores), Interne Untersuchungen. Praxisleitfaden für Unternehmen (München, Beck, 2012). 
Hartwig, N., Pficht der Unternehmensleitung zur Durchführung interner Compliance Untersuchungen im Unternehmen und Konzern, en Moosmayer, K. - HaRTwig, N. (editores), Interne Untersuchungen. Praxisleitfaden für Unternehmen (München, Beck, 2012).

Hemphill, T. - Cullari, F., Corporate Governance Practices: A Proposed Policy Incentive Regime to Facilitate internal investigationsand Self-Reporting of Criminal Activities, en Jounal of Business Ethics, 87 (2009).

Jahn, M., Ermittlungen in Sachen Siemens - SEC, en StV., 1 (2009).

Kindhäuser, U., Strafprozessrecht (2a edición, Baden-Baden, Nomos, 2006).

Knauer, C. - Buhlmann, E., Grenzen der strafprozessualen Verwertbarkeitunternehmensinterner Ermittlungen, en AnwBl. (2010).

KNAUER, K., Interne Ermittlungen. Teil I: Grundlagen”, en ZWH., 2 (2012).

Knierim, T. - Rübenstahl, M. - Tsambikakis, M. (editores), "Internal investigations”. Ermittlungen im Unternehmen (Heidelberg, Müller, 2013).

KNIERIM, T., Erfordernisse und Grenzen der "internal investigations", en RotscH (editor), Wissenschaftliche und praktische Aspekte der nationalen und internationalen Compliance-Diskussion (Baden-Baden, 2001).

Kuhlen, Grundfragen von Compliance und Strafrecht, en Kunlen, L. - Kudlich, H. - Ortiz de Urbina, I. (editores), Compliance und Strafrecht (Heidelberg, Müller, 2012).

KüHNE, Strafprozessrecht. Eine systematische Darstellung des deutschen und europäischen Strafverfahrensrechts ( 8 a edición, Heidelberg, Müller, 2010).

LANDA ZAPIRAIN, J., Ética empresarial y responsabilidad social corporativa, en GoÑI SEIN (director), Ética empresarial y códigos de conducta (Madrid, La Ley, 2011).

Maschmann, F., Vermeidung von Korruptionsrisiken aus Unternehmenssicht-Arbeitsund Zivilrecht, Corporate Governance-, en BENZ y otros (editores), Handbuch der Korruptionsprävention (München, Beck, 2007).

Mathews, A., Internal Corporate Investigations, en Obio St. L.J., 45 (1984).

McKendall, M. - De Marr, B. - Jones-Rikners, C., Ethical Compliance Programs and Corporate Illegality: Testing the Assumptions of the Corporate Sentencing Guidelines, en Journal of Business Ethics, 37 (2002).

MengeL, A., \$12: Arbeitsrechtliche Implementierung und Durchsetzung von ComplianceSystemen und Ethikregeln im Unternehmen, en HauschKa (editor), Corporate Compliance (2a edición, 2010).

Michels, K., Internal Corporate Investigations and the Truth, en Seton Hall Law Review, 40 (2010).

Momsen, C. - Grützner, T., Verfahrensregeln für interne Ermittlungen. Kritische Würdigung der Thesen der BRAK zum Unternehmensanwalt im Strafrecht, en DB., 32 (2011).

Momsen, C., "Internal investigations" zwischen Mitwirkungspflicht und strafprozessuele Selbstbelastungsfreiheit, en ZIS., 6 (2011).

Montiel, Unternehmerische Selbstreinigung: Compliance-Programme, interne Untersuchungen und Neutralisierung strafrechtlicher Risiken, en KUHLEN, L. - KudLICH, H. - Ortiz de Urbina, I. (editores), Compliance und Strafrecht (Heidelberg, Müller, 2012).

Moosmayer, K. - Hartwig, N. (editores), Interne Untersuchungen.Praxisleitfaden für Unternehmen (München, Beck, 2012),passim.; WEWERKA, F., "Internal investigations”. Private Ermittlungen im Spannungsfeld von strafprozessualen Grundsätzen und 
Anforderungen eines globalisierten Wirtschaftsstrafverfahrens; eine Problemanalyse unter besonderer Berücksichtigung des Falles Siemens (Frankfurt a. M. y otras, Peter Lang, 2012).

Moosmayer, K., Compliance. Praxisleitfaden für Unternehmen ( $2^{\mathrm{a}}$ edición, München, Beck, 2011).

Nestler, N., "Internal investigations": Definition und rechtstatsächliche Erkenntnisse zu internen Ermittlung in Unternehmen, en KNIERIM, T. - RüBENSTAHL, M. - TSAMBIKAKIS, M. (editores), "Internal investigations". Ermittlungen im Unternehmen (Heidelberg y otras, C. F. Müller, 2013).

Nieto Martín, A., Grundlagende Probleme von Compliance und Strafrecht, en Kuhlen, L. - Kudlich, H. - Ortiz de Urbina, I. (editores), Compliance und Strafrecht (Heidelberg, Müller, 2012).

PAuthner-SeIdel - StePhan, J., \$27: Compliance-Managementsysteme für Unternehmensrisiken im Bereich des Wirtschaftsstrafrechts, en HaUsCHKA (editor), Corporate Compliance ( $2^{a}$ edición, München, Beck, 2010 ).

Pickett, S., "Internal Investigations": A Basic Guide Anyone Can Use (Southern Gate, Wiley, 2008).

Potinecke, H. - Block, F., Gesellschaftliche Rahmenbedingungen und Beratung der Unternehmensführung, en KNIERIM, T. - Rübenstahl, M. - Tsambikakis, M. (editores), "Internal investigations". Ermittlungen im Unternehmen (Heidelberg, Müller y otras, 2013).

Potinecke, H. - BlOck, F., Gesellschaftliche Rahmenbedingungen und Beratung der Unternehmensführung, en KNIERIM, T. - RÜBenstahl, M. - TsambiKaKis, M. (editores), "Internal Investigations". Ermittlungen im Unternehmen (Heidelberg, Müller, 2013).

Propper, E., Corporate Fraud Investigations and Compliance Programs (New York, Oceana Publications, 2000).

ReEB, P., "Internal investigations". Neue Tendenzen privater Ermittlungen (Berlin, Duncker \& Humblot, 2011).

Rodríguez-Piñero Bravo-Ferrer, M., Derecho a la intimidad y contrato de trabajo, en La Ley, 3 (2004).

Romeo Casabona, Los delitos de descubrimiento y revelación de secretos. Especial consideración a su comisión en conexión con las nuevas tecnologías de la información y de la comunicación (Valencia, Tirant lo Blanch, 2004).

Rотsch, Criminal Compliance in Theorie und Praxis des Wirtschaftsstrafrechts (manuscrito inédito).

Roxin, I., Probleme und Strategien der Compliance-Begleitung inUnternehmen, en $S t V$., $2(2012)$.

SAHAN, O., Unternehmensinterne Untersuchungen aus rechtsanwaltlicher Perspektive, en Kuhlen, L. - Kudlich, H. - Ortiz de Urbina, I. (editores), Compliance und Strafrecht (Heidelberg y otras, Müller, 2012).

Schuhr, J. Vorbemerkung zu den $\$ \$ 133 f f$, en Knauer, C. - Kudlich, H. - SChNeIDER, H. (editores), Münchener Kommentar StPO, núm. 103 (en prensa).

Schürrle, T. - Olbers, L., Praktische Hinweise zu Rechtsfragen bei eigenen Untersuchungen im Unternehmen, en CCZ., 5 (2010), p. 178; RüBENSTAHL, M. - DeBus, S., Strafbarkeit verdachtsabhängiger E-Mail- und EDV-Kontrollen bei internal investigations? En NZWiSt., 4 (2012).

Sieber, U., Programas de "Compliance" en el Derecho penal de la empresa. Una nueva 
concepción para controlar la criminalidad de empresa (trad. Abanto - Vásquez), en Urquizo Olaechea, J. - Abanto Vásquez, M. - Salazar Sánchez, N. (coordinadores), Dogmática penal de derecho penal económico y política criminal Homenaje a Klaus Tiedemann (Lima, Fondo Editorial, 2011).

Simitis, S., $\$ 4^{a}$, en El Mismo (editor), Nomos Kommentar zum Bundesdatenschutzgesetz (7a edición, Baden-Baden, Nomos, 2011).

Spehl, S. - Grützner, T., “Corporate Internal investigations” (München, Beck, 2012), passim; RöDIGER, K., Strafverfolgung von Unternehmen, Internal investigations und strafrechtliche Verwertbarkeit von Mitarbeitergeständnissen (Frankfurt a. M., Peter Lang, 2012).

SZesny, A., Im Blickpunkt: internal investigations. Zulässigkeit und Grenzen unternehmensinterner Ermittlungen, en BB., 45 (2011).

VolK, K., Grundkurs StPO (7a edición, München, Beck, 2010).

Wauschkunn, A., Sanktionierung nach Abschluss der Untersuchungen, en MoosMAYER, K. - HARTWIG, N. (editores), Interne Untersuchungen. Praxisleitfaden für Unternehmen (München, Beck, 2012).

Weisse, M., Ausgewählte arbeitsrechtliche Aspekte und Amnistie, en Moosmayer, K. Hartwig, N. (editores), Interne Untersuchungen. Praxisleitfaden für Unternehmen (München, Beck, 2012).

WuttKe, I., Straftäter im Betrieb (München, Herbert Utz, 2010).

Wy ittul, T. - SCHuSTER, F., Datenschutzrechtliche und strafrechtliche Rahmenbedingungen der Ermittlungen, en KNIERIM, T. - RÜBENSTAHL, M. - TSAMBIKAKIS, M. (editores), "Internal investigations". Ermittlungen im Unternehmen (Heidelberg, Müller, 2013). 
